have proved to my satisfaction that the accuracy is most reasonable (at least with the Plath attachment) if four or more sights are taken in a series and a point adopted from the mean line or curve (drawn by eye). I emphasize its use on a ship because more space is available there for additional equipment, and because there is less pitching and rolling. The bubble certainly should be considered as additional equipment and not as a substitute for the natural-horizon marine sextant at sea.

\title{
REFERENCES
}

1 Rogers, Francis M. (1971). Precision Astrolabe, Portuguese Navigators and Transoceanic Aviation, Academia Internacional da Cultura Portuguesa, Lisboa.

2 Dunlap, G. D. and Shufeldt, H. H. (1969). Dutton's Navigation and Piloting. U.S. Naval Institute, Annapolis, Maryland, U.S.A.

\section{The Leap-Second of 31 December 1972}

\author{
D. H. Sadler
}

DetaILs have been given in this Journal (Vol. 25 , pages 32-42) of the new system of Coordinated Universal Time (U.T.C.) introduced on I January 1972. In accord with the agreed recommendations a positive leap-second was introduced at midnight on 30 June 1972 when the value of U.T.I-U.T.C. (DUTI) changed from $-0^{\mathbf{s}} .64$ to +0.36 . However, the Bureau International de l'Heure has now announced that another positive leap-second is to be introduced at midnight on 31 December 1972, when (according to current estimates) U.T. I-U.T.C. will be about -0.2 ; on 1 January 1973 DUT 1 will thus be +0.8 , in excess of the maximum permitted value of $0^{\text {s. }} 7$.

With the introduction of leap-seconds restricted to the last day of any month, with the necessity for a decision at least two months in advance, and with reasonable estimates (based on past records) of the changes in the speed of rotation of the Earth, $0^{s} 70$ is the minimum value that can be assigned to the maximum departure of U.T.C. from U.T.r ; the value of $0^{s} .5$, given in the original draft proposals by C.C.I.R. was misleading. The representatives of the users of U.T. I accepted (albeit reluctantly) the tolerance of $\pm 0^{s} .7$ in order to allow the convenience to other users of U.T.C. of precise one-second jumps at selected, predetermined, times; 0.7 is unduly large for many observations and results in dilution of the observations when corrections for DUTr are either not available or are not applied.

Commission 3 I (Time) of the International Astronomical Union did, however, allow for a possible increase by the statement "The maximum difference U.T.I-U.T.C. will be less than $0^{5} .7$ unless there are exceptional variations in the rotation of the Earth.' This was weakened in C.C.I.R. Report 517 (Journal, page 40 ) to 'The departure of U.T.C. from U.T. r should not normally exceed o.j.'

The present circumstances are normal; the Earth is behaving, and U.T. IU.T.C. is decreasing, in an expected and normal manner. It would have been easy to have kept well within the permitted maximum by deferring the intro- 
duction of the leap-second until the last day of February, March or April. It can only be assumed that the mild 'preferably 31 December and/or 30 June' of Report 517 has been accorded an overriding importance which cannot be justified; the present tolerance of o. 7 allows, in many cases, a choice between two or three months (thus allowing the preference, as in June 1972), but if the choice were restricted to December or June the maximum permitted value would have to be substantially increased.

Apart from practical considerations (the code for the transmission of DUTr makes no provision for values as large as 0.8 !) this 'fait accompli' must raise the whole question of the inviolability of agreements, especially those reached as the result of compromise between different interests. It would appear that the agreement reached on U.T.C., as expressed by the recommendations and reports of C.C.I.R., has been breached-unnecessarily and deliberately; and this could well foreshadow still further steps in the escalation process. There will undoubtedly be protests against this 'fait accompli'; in particular the matter will be discussed at the General Assembly of the International Astronomical Union (Sydney, August 1973). It is hoped that C.C.I.R., and other organizations concerned, will ensure that the instructions in C.C.I.R. Report 517 are strictly adhered to in the future.

Note. The above was written in November $197^{2}$. At its meeting on 17 January 1973 the Council of the Institute adopted the following resolution, which has been sent to the Minister for Posts and Telecommunications (the Right Hon. Sir John Eden, Bt.):

\section{RESOLUTION}

The Royal Institute of Navigation has been informed that the introduction of a leap-second into the time-signal transmissions at midnight on 31 December 1972 (instead of 28 February, 31 March or 30 April) has resulted in the departure of the transmitted time (UTC) from UTI (essentially GMT) of greater than the permitted tolerance of 0.5 , contrary to the assurances given that this would be exceeded only as a result of a large unforeseen change in the speed of rotation of the Earth.

The Institute notes that no provision was made in the primary time-signal transmissions for coded corrections of greater than $0^{s} .7$, and that many users of UTI will have to accept larger errors than they have been led to expect.

The Institute expresses its deep concern that the compromise agreement between the various users of UTC should have been broken so soon after its introduction; it calls upon the responsible national and international organizations to take the action necessary to ensure strict adherence to this and similar agreements.

Later information indicates that, in order to meet the requirements of one National Member of C.C.I.R., the word 'normally' was introduced into the adopted text of Report 517 deliberately to allow a slight increase over $0^{5} 7$ in the departure of U.T.C. from U.T.I. in anticipation that thereby the introduction of leap-seconds could be restricted to 31 December and/or 30 June. Faced with a difficult decision, in October 1972 the Director of the Bureau International de l'Heure must accordingly be absolved from any criticism that he did not strictly follow the terms of that Report. The first consultations towards a recision of the instructions in Report 517 have now been started by a committee of the C.C.I.R. 